\title{
Role of plasma growth factor in the healing of chronic ulcers of the lower legs and foot due to ischaemia in diabetic patients
}

\author{
Tomasz Miłek ${ }^{1}$, Krzysztof Baranowski ${ }^{1}$, Piotr Zydlewski ${ }^{1}$, Piotr Ciostek ${ }^{1}$, Krzysztof Mlosek $^{2}$, Wojciech Olszewski ${ }^{3}$
}

${ }^{1} 1^{\text {st }}$ Department of General and Vascular Surgery, $2^{\text {nd }}$ Faculty of Medicine, Medical University of Warsaw, Warsaw, Poland ${ }^{2}$ Department of Imaging Tests, Medical University of Warsaw, Warsaw, Poland

${ }^{3}$ Department of Pathomorphology, Mazovian Bródno Hospital, Warsaw, Poland

\begin{abstract}
Introduction: It has been demonstrated that plasma growth factor (PGF) responsible for proliferation of smooth muscle cells and fibroblasts significantly shortens treatment duration.

Aim: To determine the role of human growth factor in the healing of ulcers due to ischaemic diabetic foot syndrome (DFS) following previous angioplasty of the blood vessels of the lower leg and foot.

Material and methods: The study group included 50 patients with ischaemic diabetic foot complicated by lower leg ulcers in which angioplasty of the stenotic arteries in the distal lower leg and foot was performed. It has been assumed that the area of the ulcer cannot exceed $5 \mathrm{~cm}^{2}$. Following surgical debridement, each patient received platelet-rich plasma in the form of dressings applied on an ulcer, followed by hydrocolloid dressings. Each dressing was replaced after 10 days, and this procedure was repeated after 20 and 30 days of treatment. The control group included 50 patients with ischaemic diabetic foot complicated by an ulcer up to $5 \mathrm{~cm}^{2}$. Angioplasty of the lower leg arteries was also performed in this group. However, after surgical debridement, wounds were covered with hydrocolloid dressings.

Results: After 3 months of combined treatment, all wounds in the study group healed whereas in the control group, only wounds of the smallest size healed.

Conclusions: Combined treatment of ulcers due to ischaemic DFS with endovascular procedures to re-establish blood flow to the vessels and dressings with autologous platelet-rich plasma significantly shortens the healing time.
\end{abstract}

Key words: diabetic foot, ulcers, human growth factor, angioplasty, angiosomes.

\section{Introduction}

Diabetic foot syndrome (DFS) is a long-term complication of diabetes mellitus, which develops in $5-20 \%$ of patients. Diabetic foot syndrome is diagnosed in $12-18 \%$ of patients with type 2 diabetes, and in $0.6-2 \%$ of patients with type 1 diabetes. Seventy percent of these patients are diagnosed with peripheral neuropathy [1, 2]. In $30 \%$ of patients DFS is due to ischaemia of arterial aetiology (10\%) as well as mixed, arterial-neuropathic aetiology (20\%). One of the consequences of chronic ischaemia is the formation of foot ulcers due to an increased atherosclerotic lesion [3, 4]. As a result of development in endovascular techniques, it is therefore possible to effectively treat this particular diabetic complication. Plastic surgeons first introduced the concept of angiosomes as a region of the skin supplied by a particular artery and as a result of this concept it has become significantly easier to interpret ischemic changes. Four foot angiosomes are supplied by three lower leg arteries [5]. After revascularization, the percentage of small amputation is significantly reduced. However, the full healing of ulcers requires conventional treatment in the form of dressings and targeted antibiotic therapy. It is a long-term process that on average takes approximately 6 months [6]. In order to speed up this process, researchers have conducted studies on the use of growth factors in wound healing.

It has been demonstrated that plasma growth factor (PGF) such as platelet derived growth factor (PDGF) which is responsible for cell proliferation, epidermal growth factor (EGF) for angiogenesis, vascular endothe-

Address for correspondence: Tomasz Miłek MD, PhD, $1^{\text {st }}$ Department of General and Vascular Surgery, $2^{\text {nd }}$ Faculty of Medicine, Medical University of Warsaw, 8 Kondratowicza St, 03-242 Warsaw, Poland, phone: +48 604 422 345, e-mail: tomasz_milek@wp.pl Received: 3.04.2016, accepted: 10.09.2016. 
lial growth factor (VEGF) for smooth muscle cells and fibroblasts growth factor (FGF) significantly shortens treatment duration [7-9]. Among all plasma growth factors, recombinant PDGF-BB maintains its activity in the environment of the wound the longest while others PGF undergo proteolysis faster. The effectiveness of early treatment has been examined in many medical centres; however, there are only few reports on late treatment of wounds with growth factors. While early adjuvant treatment with PGF leads to healing in approximately $80 \%$ of wounds [10, 11], the long-term use of conventional treatment with this agent has not been tested.

\section{Aim}

This study was aimed to determine the role of human growth factor in the healing of ulcers due to ischaemic DFS following previous angioplasty of the blood vessels of the lower leg and foot.

Table 1. Patients characteristics

\begin{tabular}{|c|c|c|c|}
\hline Parameter & Study group & \multicolumn{2}{|c|}{ Control group } \\
\hline Number of patients & 50 & & 50 \\
\hline Gender (men/women) & $34 / 16$ & & $9 / 11$ \\
\hline Mean age of women/men & $\begin{array}{l}75(55-86) / \\
68(53-89)\end{array}$ & $\begin{array}{l}71(5) \\
65(5\end{array}$ & $\begin{array}{l}57-79) / \\
(54-79)\end{array}$ \\
\hline Cigarette smokers & 19 & & 17 \\
\hline Arterial hypertension & 26 & & 21 \\
\hline Coronary heart disease & 5 & & 7 \\
\hline $\begin{array}{l}\text { History of myocardial } \\
\text { infarction }\end{array}$ & 2 & & 1 \\
\hline $\begin{array}{l}\text { Atherosclerotic disease of } \\
\text { the arteries of the lower } \\
\text { extremities }\end{array}$ & 24 & & 39 \\
\hline Renal failure & 15 & & 17 \\
\hline Onset of DM (mean) [years] & $7-21(14)$ & $9-18$ & $18(16)$ \\
\hline Insulin - number of patients & 47 & & 49 \\
\hline Oral hypoglycaemic drugs & 3 & & 1 \\
\hline $\mathrm{HbA}_{1 \mathrm{c}}$ & $\begin{array}{c}\text { Prior to After 2-3 } \\
\text { treat- months } \\
\text { ment of treat- } \\
\text { ment }\end{array}$ & $\begin{array}{l}\text { Prior to } \\
\text { treat- } \\
\text { ment }\end{array}$ & $\begin{array}{c}\text { After 2-3 } \\
\text { months of } \\
\text { treat- } \\
\text { ment }\end{array}$ \\
\hline $6.1-6.5$ & 29 & 2 & 25 \\
\hline $6.6-7.0$ & 21 & 9 & 19 \\
\hline $7.1-7.5$ & 15 & 22 & 2 \\
\hline $7.6-8.0$ & 3 & 8 & 4 \\
\hline $8.1-8.5$ & 3 & 1 & 0 \\
\hline $8.6-9.0$ & 0 & 0 & 0 \\
\hline $9.1-10.0$ & 0 & 0 & 0 \\
\hline $10.1-11.0$ & 0 & 0 & 0 \\
\hline $11.1-12.0$ & & 1 & 0 \\
\hline
\end{tabular}

\section{Material and methods}

The study included patients with ischaemic DFS complicated by ulceration of the lower leg and/or foot, in addition the ulcers did not exceed $5 \mathrm{~cm}^{2}$ in size and with the presence of clinical symptoms of lower leg ischaemia. The initial time the ulcers developed was not an important factor as most ulcers were recurring. The control group was treated by conventional treatments. Permission to use this procedure was given by the Bioethics Committee of the Medical University of Warsaw. After obtaining the approval of the growth factor preparation, informed consent was obtained from patients. The study group included 50 patients with ischaemic DFS complicated by lower leg ulceration, in whom angioplasty of the stenotic artery of the distal lower leg and foot was performed. Inclusion criteria for patients in the study included: ulcer $<5 \mathrm{~cm}$, lower limb ischaemia clinically and radiologically proven by angioCT, condition after a successful revascularization and creatinine $<1.0 \mathrm{mg} / \mathrm{dl}$.

Exclusion criteria included: $<18$ years of age, ulceration $>5 \mathrm{~cm}$, venous ulcer and ulcer without ischaemia. The duration of ulcers in patients in the study ranged from 6 to 16 months (average: 7.3 months). The area was calculated by tracing the size of ulcer on a carbon paper and then reflecting it on an already scaled marked paper. The maximum size of the wound treated was determined by the size of the dressing present in the healing kit. Following surgical debridement, each patient received platelet-rich plasma in the form of dressings applied on the ulcer, then covered with hydrocolloid dressings (AQUA$\mathrm{CEL}^{\oplus}$ Ag SURGICAL). Platelet-rich plasma was obtained by taking $18 \mathrm{ml}$ of the patient's blood. The blood was then centrifuged in order to separate erythrocytes and leukocytes from plasma containing platelets. A branded reagent was given to the plasma, which activated the platelets for the production of growth factors. The resulting platelet-rich plasma was placed on the wound. A dressing was maintained for 10 days, and then replaced with a new one. This procedure was repeated after 20 and 30 days of treatment. The ulcer was assessed on 4 different occasions, each time documenting its appearance and size, depth of wound which was assessed with an ultrasound probe with a frequency of $50 \mathrm{MHz}$, histological granulation process, skin formation and the formation of wound vessels.

The control group included 50 patients with ischaemic DFS complicated by an ulcer up to $5 \mathrm{~cm}^{2}$. Angioplasty of the arteries of the lower leg and foot was also performed in this group. However, after surgical debridement, wounds were covered with hydrocolloid dressings (AQUACEL ${ }^{\oplus}$ Ag SURGICAL). The dressing was also replaced every 10 days, and healing outcomes were assessed based on changes in the size, depth of wounds, granulation tissue formation and epithelialisation of ulcers. Dressings with platelet rich plasma (Regeneris) was 
introduced in 2012. Since then, all patients with diabetic foot ulceration of ischaemic aetiology have been given this type of dressing. The control group included patients who had been treated since 2012, and thus received hydrocolloid gel dressings (AQUACEL ${ }^{\oplus}$ Ag SURGICAL) only. In both groups, the degrees of ischaemia in the lower limb were assessed based on the history, distance of claudication, ultrasound, and computed tomography angiography of the aorta and lower limb arteries. Dry necrosis of the wound was present in both of the groups. Population, patient characteristics and co-morbidities in both groups are presented in Table 1.

The depth of ulcers was evaluated on the basis of the University of San Antonio scale. In the study group, 37 patients presented with degree I stage $C$ and 13 patients with degree II stage $\mathrm{C}$. The control group included 34 patients with degree I stage $C$ and 16 patients with degree II stage $\mathrm{C}$. The duration of the treatment of the ulcers was between 6 to 16 months. After normalization of blood glucose, percutaneous transluminal angioplasty (PTA) was performed. Due to renal failure, carbon dioxide was used as a contrast agent during PTA. After the initial angiography we tried to improve the direct flow to the foot ulcer according to individual arteries (angiosomes) that supplied the area. When recanalisation of the vessels that directly supply the ulcer was impossible, we attempted to improve the blood flow from collateral circulation by dilating the collateral artery supplying the ulcer. On the next day, hydrogel dressings with or without growth factors were used. Compression of a punctured artery was removed the next day. Patients were discharged for further outpatient treatment on the $3^{\text {rd }}$ day of hospitalization. Long-term outcomes were assessed 3 and 6 months later. Foot X-rays were performed in all patients in both groups. Bone destruction was observed in 13 patients in the study group and 18 patients in the control group. After orthopaedic consultation, foot stabilizing shoes were used in 2 patients in the study group and 3 patients in the control group. After first admission, lower digit amputations were performed in 5 patients in the study group and 3 in the control group. Forefoot ischaemia resulting in foot amputations during 6 months' observation was noted, regardless of repeated attempts of endovascular revascularization, and peripheral venous grafts were seen in 5 patients in the study group and 7 patients in the control group. Twenty percent of patients in the study group and $23 \%$ in the control group presented with neuropathic signs in neurological examination.

\section{Results}

The technical success of recanalisation which was evaluated on the basis of arteriography of the lower leg arteries was observed in all patients in both groups. Patency of the main artery was restored in $89 \%$ of the pa-

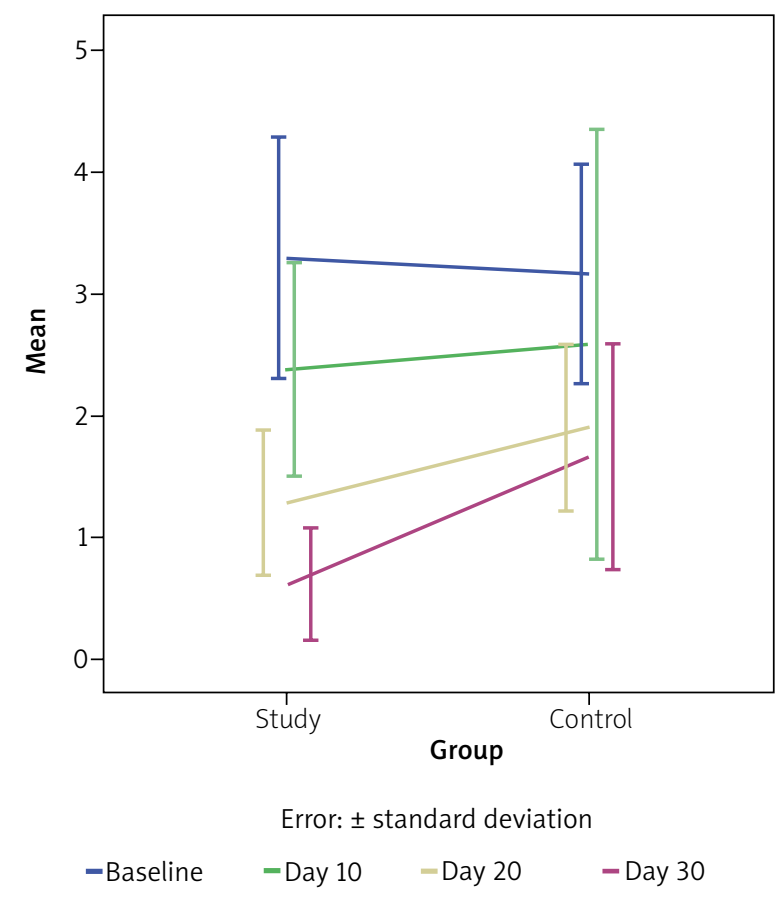

Figure 1. Results after treatment

tients in the study group and $75 \%$ in the control group. In $11 \%$ of cases in the study group and in $25 \%$ of cases in the control group, blood supply was delivered to an ulcer as a result of recanalisation of the collateral circulation. Most commonly observed foot ulcers were located in the region of angiosome, supplied by the dorsalis pedis artery. This artery was revascularised in all patients as the dorsalis pedis artery is a direct continuation of the anterior tibial artery. The most difficult area to restore blood circulation in the foot was the angiosome which was supplied by the lateral plantar artery. In this region ulcers were the largest and healing time was the longest. In this case, the blood flow was most commonly restored via collateral circulation from the arteries of the medial plantar angiosome.

Ulcers in both groups were divided into four categories depending on the initial ulcer size. The results of the treatment after restoring blood circulation, administration of growth factors and line graph taking into account standard deviations are shown in Figure 1. In addition, results of foot ulcer treatments with regard to location of the ulcer, blood flow to a respective angiosome and healing rate are presented in Figure 2. Long-term outcomes assessed after 3 and 6 months are presented in Table 2.

\section{Discussion}

For many years the main problem, which prevented effective treatment of ischemic ulcers in diabetic patients, has been the small size of the vessels affected by the disease. Although surgical treatment is still consid- 
Table 2. Follow-up results

\begin{tabular}{lcccccccc}
\hline Parameter & \multicolumn{3}{c}{ Study group } & \multicolumn{4}{c}{ Control group } \\
\hline Mean initial wound size $\left[\mathrm{mm}^{2}\right]$ & 1.9 & 2.6 & 3.7 & 4.6 & 1.9 & 2.9 & 3.3 & 4.9 \\
\hline Mean wound size after 30 days $\left[\mathrm{mm}^{2}\right]$ & 0.5 & 0.8 & 1.1 & 1.2 & 0.7 & 1.2 & 1.6 & 2.0 \\
\hline Mean wound size after 3 months $\left[\mathrm{mm}^{2}\right]$ & Healed & Healed & Healed & Healed & Healed & 0.5 & 0.7 & 1.1 \\
\hline Mean wound size after 6 months $\left[\mathrm{mm}^{2}\right]$ & & & & & & Healed & Healed & 0.4 \\
\hline
\end{tabular}

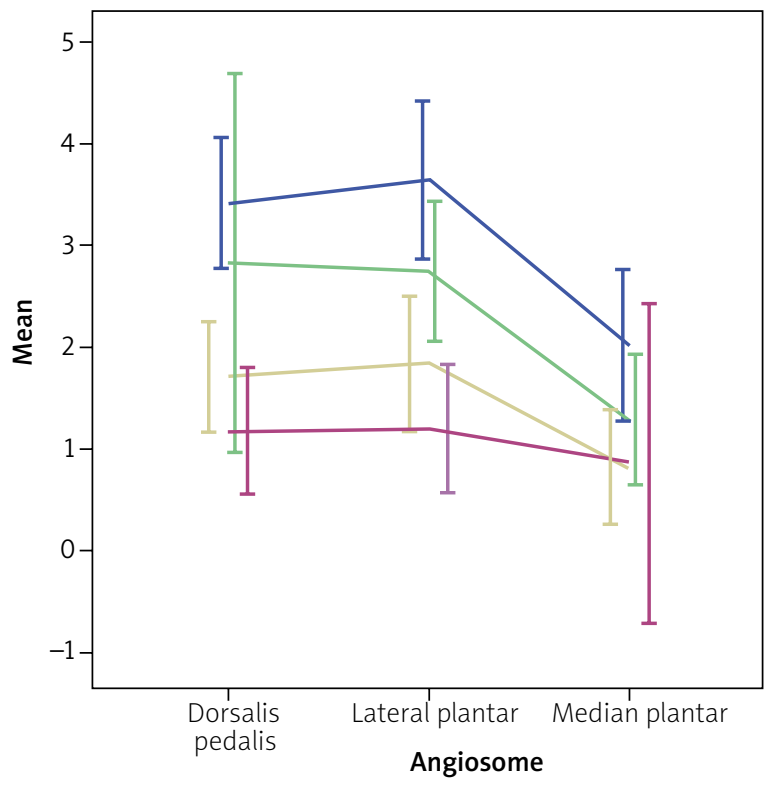

Error: \pm standard deviation

$$
\text { -Baseline -Day } 10 \quad \text {-Day } 20 \quad \text { - Day } 30
$$

Figure 2. Results of treatment

ered the gold standard for patients with DFS, the role of endovascular treatment is ever-increasing [12-14]. Initially, PTA was reserved only for patients with an extremely high pathologic burden who were not qualified for surgical treatment [15]. Currently, endovascular treatment of changes in the arteries below the knee is considered an alternative method of surgical treatment in many medical centres. One of the first largest studies evaluating the efficacy of treatment of lesions in the arteries below the knee was conducted by Italian specialists. They reviewed 993 patients in whom PTA of the lower leg blood vessels was performed. The group of patients who were subjected to this procedure included 17 cases of amputations above the ankle $(1.7 \%)$, whereas small amputations were performed in 478 (48\%) patients. After 5 years, the initial patency of the arteries treated with PTA was $88 \%$. Restenosis of the arteries by angioplasty accompanied by clinical symptoms was observed in 87 patients. Results of these studies reveal that endovascular procedures are associated with high efficacy [16, 17]. In 1987, Taylor and Palmer presented a model dividing the skin of the foot into angiosomes. These areas are supplied by three main arteries of the lower legs $[18,19]$. The ability to restore blood flow back into the angiosome, where the ulcer is present is critical for wound healing. The use of modern microcatheters increases the effectiveness of angioplasty of anatomical vessels leading to angiosomes or patency of collateral vessels. The effectiveness of restoring patency of the corresponding vessels in the lower legs is around $65-90 \%$ [20-22]. These values are comparable to our own results ( $89 \%$ in the study group and $75 \%$ in the control group). However, there are no reports in the literature on the efficacy of blood flow restoration as a result of recanalisation of collateral circulation to the ulcer area. In $11 \%$ of the study group and $25 \%$ of the control group, a non-anatomical route was used to provide blood flow to the ulcer. The efficacy of ulcer treatment in such cases was comparable to an anatomical route. It can be explained by the fact that the diameter of blood vessels in the physiological circulation and in the collateral circulation that has formed for many years of the disease is comparable. Many researchers have attempted to develop a classification of local lesions that are present in DFS, however none of these classification made it easier to select procedures or evaluate the expected results. These classifications focused mainly on the depth of ulcers, thus did not take into account relevant factors, such as ischaemia and infection [23-25]. A team of specialists from San Antonio suggested the rating specifying not only the depth of the ulcer (degree), but also the presence of ischaemia and infection (stage) [26, 27]. This scale is used to classify ulcers presented in DFS as it allows monitoring of the treatment and better understanding between different medical specialists dealing with patients with DFS. Patients with ischemic diabetic foot ulceration in the distal extremity are presenting one of the symptoms of critical limb ischaemia. It is characterized by chronic inflammation and is resistant to topical treatments. Studies have demonstrated that wound healing is promoted (up to 50\%) when a wound surface is wet. Therefore, the standard is the use of modern hydrogel, hydrocolloid and alginate dressings. However, the rate of poor wound healing (when the healing lasts more than 4 weeks) is high and reaches $10 \%$ to $40 \%$. Currently, 
there have been intense studies on the use of growth factors in wound healing. It has been demonstrated that PGF is responsible for proliferation of smooth muscle cells and fibroblasts, which significantly shortens treatment duration [28-30]. Recombinant PDGF-BB remains active in the wound environment the longest, whereas other factors are usually subject to proteolysis under such conditions. The efficacy of early treatment has been studied in many medical centres; however, there are only few reports on late treatment of wounds with growth factors. Early adjuvant treatment with PGF leads to healing in approximately $80 \%$ of wounds; but long-term administration of conventional treatment with PGF has not been documented.

Chronic wounds present for more than 1 month require treatment with growth factors. When these growth factors were used we observed not only improvement in healing, but also changes of ulcer characteristics. Wound discharge became lighter in colour, resembling plasma. The bottom of the ulcer which was previously flat and covered with necrosis and fibrin had become rough and filled with granulation tissue. Swelling and inflammation were significantly reduced. The use of PGF as a biological dressing significantly promoted wound healing. This is due to elevated levels of numerous factors promoting wound healing, such as VEGD, IGF-1, and TGF- $\beta$. In our study, the difference in surface area of the healing wound was the highest in those wounds with a diameter of 2 to $4 \mathrm{~cm}$. Ulcers located in angiosomes of the foot surface area were the most difficult to heal. This was associated with constant compression of ulcers as well as poor blood flow to some parts of these plantar angiosomes. The time when dressings were replaced in the study group depended on the life span of blood platelets. The life span for blood platelets is between 7 to 10 days. Thus, this period determines how long a dressing can be kept on a wound. The highest concentrations of factors stimulating wound healing are observed on the $2^{\text {nd }}-3^{\text {rd }}$ day. These levels are maintained for a further 3-4 days.

Before starting treatment the wound was assessed histologically. During this period the wounds are avascular with plenty of dead cells. The first period of healing, namely formation of the granulation tissue, was observed after 10 days. This process was characterised by adequate blood flow to the tissues but additionally there was reduction in wound discharge. When compared to the initial phase (Figure 1) we observed that the amount of fibrin at the bottom of the wound had been reduced, furthermore there was a reduction of oedema in wound edges. Cytokines are responsible for such changes, and their levels in wounds are increased. Along with plateletderived growth factor, vascular permeability factor was also included in the product that had been administered. They were combined with bactericidal factors with chemotactic properties forming the so-called "platelet atmosphere", which are responsible for the formation of pros- taglandins from acids that have been formed de novo in blood platelets. Prostaglandins have potent vasodilator properties. They stimulate the formation of the epidermis and dermis in the second phase of wound healing. In this period it is possible to observe a dense network of supplying blood vessels, and granulation tissue. The third phase of healing, namely the formation of the dermis, was observed after 30 days of treatment in our study. The dermis was formed on the basis of young epidermis and vessel-rich granulation tissue. In the study group, ulcers were healed within 3 months. In the control group, wounds up to $2 \mathrm{~cm}$ were healed, whereas larger wounds required further treatment. There were no complications observed during treatment with a platelet-containing product. Furthermore, small traumas to wounds did not result in delayed healing. It was not necessary to apply epidermal grafts on wounds, although their placement on fresh granulation tissue would have probably accelerated wound healing. The cost of a single dressing with platelet-derived growth factor is $75 €$, while the cost of AQUACEL ${ }^{\oplus}$ Ag SURGICAL dressing is $20 €$. Neurological examinations were performed in all patients, and were carried out on an outpatient basis at different treatment intervals. Most neurological examinations were carried out on the request of the diabetologist. Majority of the symptoms experienced included paraesthesia, painful muscle cramps, muscle weakness and reduced tendon reflexes. The treatment also included normalization of blood glucose levels, in addition to treatment of symptoms with the use of angiotensin-converting enzyme inhibitors and $\alpha$ lipoic acid. Long-term and severe symptoms included paraesthesia and burning sensation of the foot leading to the development of depression. The firstchoice of antidepressants given to these patients were amitriptyline and imipramine.

The combined treatment of ulcers due to ischaemic DFS with endovascular procedures to re-establish blood flow to vessels and dressings with autologous plasmarich growth factors significantly shortens the healing time.

\section{Conflict of interest}

The authors declare no conflict of interest.

\section{References}

1. Abbott CA, Carrington AL, Ashe H, et al. The North-West Diabetes Foot Care Study: incidence of, and risk factors for, new diabetic foot ulceration in a community - based patient cohort. Diabet Med 2002; 19: 377-84.

2. Abbott CA, Vileikyte L, Williamson S, et al. Multicenter study of the incidence of and predictive risk factors for diabetic neuropathic foot ulceration. Diabetes Care 1998; 21: 1071-5.

3. Wild S, Roglic G, Green A, et al. Global prevalence of diabetes: estimates for the year 2000 and projections for 2030. Diabetes Care 2004; 27: 1047-53. 
4. Shaw JE, Sicree RA, Zimmet PZ. Global estimates of the prevalence of diabetes for 2010 and 2030. Diabetes Res Clin Pract 2010; 87: 4-14.

5. International Diabetes Federation IDF Diabetes Atlas. $4^{\text {th }}$ ed. Brussels, Belgium, 2009.

6. Edmonds M, Korzon-Burakowska A. Wielodyscyplinarne poradnie stopy cukrzycowej. Diabetol Prakt 2005; 2: 81-3.

7. Schofield CJ, Libby G, Brennan GM, et al. Mortality and hospitalization in patients, after amputation: a comparison between patients with and without diabetes. Diabetes Care 2006; 29: 2252-6.

8. Moxey PW, Hofman D, Hinchliffe RJ, et al. Epidemiological study of lower limb amputation in England between 2003 and 2008. Br J Surg 2010; 97: 1348-53.

9. Hinchliffe RJ, Andros G, Apelqvist J, et al. A systematic review of the effectiveness of revascularization of the ulcerated foot in patients with diabetes and peripheral arterial disease. Diabetes Metab Res Rev 2012; 28: 179-217.

10. Tartaglia E, Lejay A, Georg Y, et al. Results of isolated infrapopliteal percutaneous transluminal angioplasty for critical limb ischemia in high-risk diabetic patients. Vascular 2015; 24: 515-22.

11. Conte MS. Challenges of distal bypass surgery in patients with diabetes: patient selection, techniques, and outcomes. J Am Podiatr Med Assoc 2010; 100: 429-38.

12. Good DW, Al Chalabi H, Hameed F, et al. Popliteo-pedal bypass surgery for critical limb ischemia. Ir J Med Sci 2011; 180: 829-35.

13. Pomposelli FB, Kansal N, Hamdan AD, et al. A decade of experience with dorsalis pedis artery bypass: analysis of outcome in more than 1000 cases. J Vasc Surg 2003; 37: 307-15.

14. Conte MS, Bandyk DF, Clowes AW, et al. Results of PREVENT III: a multicenter, randomized trial of edifoligide for the prevention of vein graft failure in lower extremity bypass surgery. J Vasc Surg 2006; 43: 742-51.

15. Trans Atlantic Inter-Society Consensus (TASC). Section D: Chronic critical limb ischaemia. Eur J Vasc Endovasc Surg 2000; 19: 144-63.

16. Faglia E, Dalla Paola L, Clerici G, et al. Peripheral angioplasty as the first-choice revascularization procedure in diabetic patients with critical limb ischemia: prospective study of 993 consecutive patients hospitalized and followed between 1999 and 2003. Eur J Vasc Endovasc Surg 2005; 29: 620-7.

17. Bosiers M, Scheinert D, Peeters P, et al. Randomized comparison of everolimus-eluting versus bare-metal stents in patients with critical limb ischemia and infrapopliteal arterial occlusive disease. J Vasc Surg 2012; 55: 390-8.

18. Serra R, Grande R, Scarcello E, et al. Angiosome targeted revascularisation in diabetic foot ulcers. Int Wound J 2015, 12: 555-8.

19. Attinger CE, Evans KK, Bulan E, et al. Angiosomes of the foot and ankle and clinical implication for limb salvage reconstruction, incision, and revascularization. Plast Reconstr Surg 2006; 117: 216S-93S.

20. Neville RF, Attinger CE, Bulan EJ, et al. Revascularization of a specific angiosome for limb salvage: does the target artery matter? Ann Vasc Surg 2009; 23: 367-73.

21. Iida O, Nanto S, Uematsu M, et al. Importance of the angiosome concept for endovascular therapy in patients with critical limb ischemia. Catheter Cardiovasc Interv 2010; 75: 830-6.

22. Manzi M, Cester G, Palena IM, et al. Vascular imaging of the foot: the first step toward endovascular recanalization. Radiographics 2011; 31: 1623-36.
23. Marti-Carvajal A, Gluud C, Nicola S, et al. Growth factors for treating diabetic foot ulcers. Cochrane Database Syst Rev 2015; 10: CD008548.

24. McAleer JP, Sharma S, Kaplan EM, et al. Use of autologous platelet concentrate in a nonhealing lower extremity wound. Adv Skin Wound Care 2006; 19: 354-63.

25. Reinke JM, Sorg H. Wound repair and regeneration. Eur Surg Res 2012; 49: 35-43.

26. O'Meara S, Cullum N, Majid M, et al. Systematic reviews of wound care management: (3) antimicrobial agents for chronic wounds; (4) diabetic foot ulceration. Health Technol Assess 2000; 4: 1-237.

27. de Leon JM, Driver VR, Fylling CP, et al. The clinical relevance of treating chronic wounds with an enhanced near-physiological concentration of platelet-rich plasma gel. Adv Skin Wound Care 2011; 24: 357-68.

28. Frykberg RG, Driver VR, Carman D, et al. Chronic wounds treated with a physiologically relevant concentration of platelet-rich plasma gel: a prospective case series. Ostomy Wound Manage 2010; 56: 36-44.

29. Gao F, Wang JX, Han Y. Research advance on application of platelet-rich plasma in wound repair - review. Zhonggou Shi Yan Xue Za Zhi 2009; 17: 840-3.

30. Allen RJ Jr, Soares MA, Haberman ID, et al. Combination therapy accelerates diabetic wound closure. PLoS One 2014; 9: e92667. 